\title{
New concept of quality management in shipbuilding
} Ionel Dănuț SAVU ${ }^{1, a^{*}}$, Sorin Vasile SAVU ${ }^{2, b}$, Mihai Gheorghe GHIBA ${ }^{3, c}$

${ }^{1,2,3}$ Department of Engineering and Management of Technological Systems, Faculty of Mechanics, University of Craiova, $1^{\text {st }}$ Calugareni Street, Drobeta Turnu Severin, Mehedinti County, Romania

\author{
adanut.savu@imst.ro, bsorin.savu@imst.ro, ’gomog44@yahoo.com
}

Keywords: Quality Management, ship structure, Inspection test Plan, qualification of personnel, qualification of procedures

\begin{abstract}
Fabrication in shipbuilding faces important requirements from the quality point of view, due to potential risks specific to the exploitation of the naval structures. Quality Management becomes important tool to reduce the susceptibility to failure of different components of the structures. Specific processes are involved in shipbuilding and the Quality Management should address all of them. Inspection Test Plan (ITP) should be the first step of the Quality Management and that step is previous to any action related to fabrication. Sometimes, that step is necessary to be done even before the design of the naval structure. The most important processes which are required to answer to the ITP are welding, testing of welds, treating distortions and painting. For each of them, qualification of personnel, qualification of the involved procedures, qualifications of the materials and consumables should be evaluated. Operational procedures for every step of the fabrication and for auxiliary operations should be elaborated, discussed and approved by the Quality Manager.
\end{abstract}

\section{Introduction}

Shipbuilding is the most important way of worldwide transportation of goods. Failures in the structure of ship could involve three types of damages: human life loss, damage of the shipped goods and ecological issues from minor to huge disasters related to the marine or coastal or inland rivers environment. Due to all of these issues, failures in the naval structures should be avoided and that starts with the fabrication and it ends with the exploitation [1].

The fabrication specific to shipbuilding involves cutting processes, welding processes, removal of the distortions and painting processes, together with the auxiliary processes related to the application of the main operations. Standards are covering the main requirements regarding the quality but specific conditions usually exceed the requirements involved by the standards. These situations are solved by elaborating plan of testing which aims to reveal the characteristics under discussion. The document is the base of the investigations which will be applied before, during and after fabrication. To all the points of the document, the welded structures producer should continuously answer, until the ship or the naval structure is delivered.

The paper aims to present improved concept of Quality Management (QM) dedicated to fabrication specific to shipbuilding.

\section{Inspection test plan}

To build a ship or other type of naval structure means processing of specific materials. The main processes which are involved in the fabrication of a naval structure are: the cutting of the pieces from the raw materials, the welding of the pieces, the examination of the pieces and of the welds, the straightening of the pieces which suffered distortions due to processing and after the building of the structure processes to protect the ship from corrosion are necessary, so blasting and painting are the last two very important processes (Figure 1).

Figure 1 shows the main relations which are acting when project is put under implementation by the shipyard. It can be considered two levels of relations: Management level relations and Coordination level relations. 


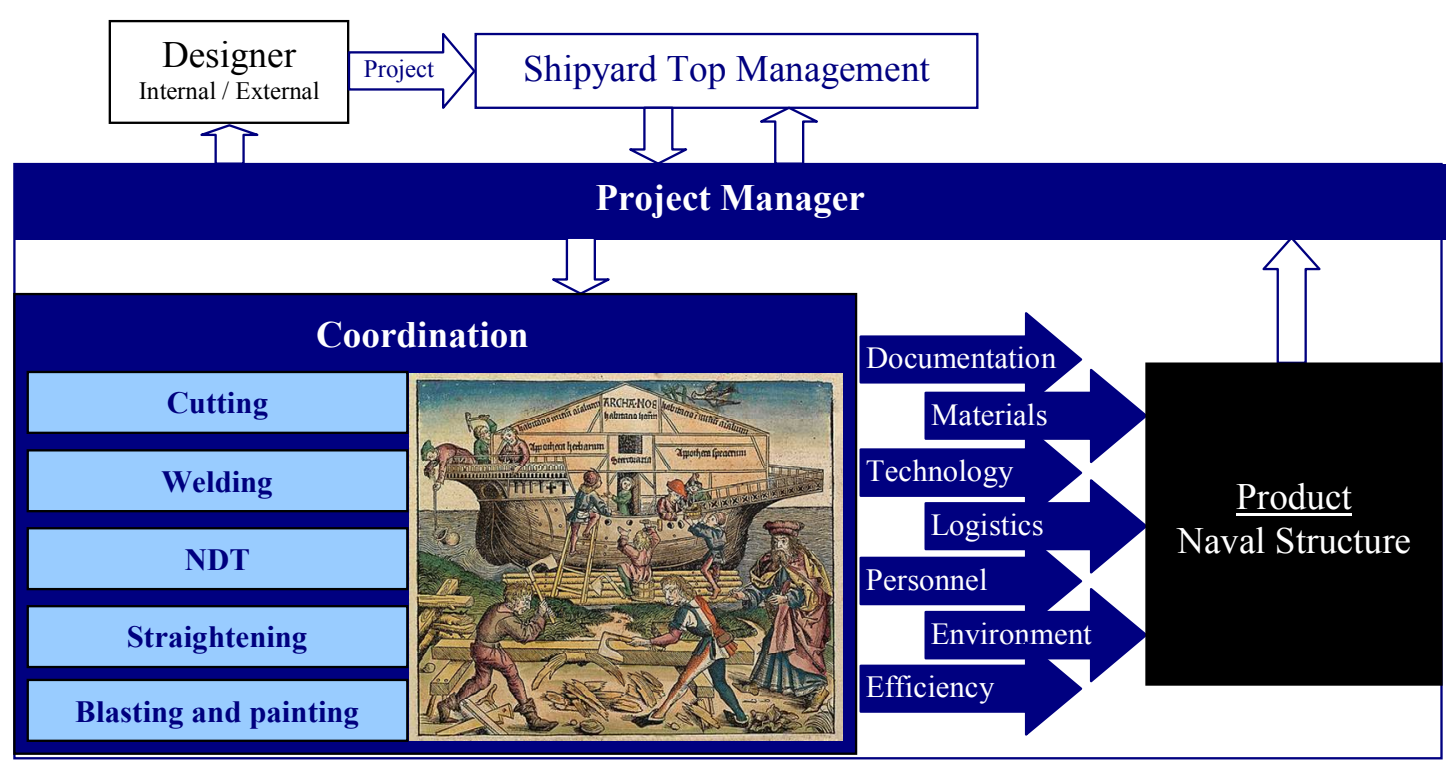

Fig. 1 Relations activated during the fabrication

The project enter is the start. The Shipyard Top Management receives the project and technical and economical analyzing process is performed. Depending on the type and the complexity of the project, Project Manager is chosen by the Top Management. The Project Manager will be in charge and he will apply direct surveillance on the Coordination of the processes.

The second level is related to the Coordination of the involved processes. Group of five main processes presented above will be in full opera during fabrication. The coordination should consider the controlling of the following outputs: documentation related to the recordings required by the quality system, materials involved in fabrication, technology to be involved in fabrication, logistics necessary to implement the technology (equipment, devices, tools, etc.), personnel with specific types and levels of qualification, impact to the environment and the last but not least the efficiency of the fabrication $[2,3,4]$.

A new concept of QM is based on opposite vision comparing to the actual and usual vision. The usual organizing of the QM is to build step by step the fabrication taking account of the minimum requirements which will be able to prove the quality of the naval structure [1,5].

The new concept is to start with planning the inspection. What inspection is necessary? This is the first question, a shipyard to put itself. The answer could be given by developing accurate plan of tests dedicated to the inspection required by the standards and/or by the beneficiary (Figure 2).

The Inspection Test Plan (ITP) is the document which the producer should meet all the time since receiving the project to build, until the delivering of the product. ITP covers all the requirements for the fabrication and installation of General Structural Components such as PLEM Structures, Temporary Aids, Piggyback Platforms, Stairways, etc.

Not only the shipyard but the beneficiary of the naval product or the surveyor nominate representatives and the representatives shall have the right to undertake inspection or testing of the goods or services, during any stage of the fabrication at which the quality of the finished goods may be affected, and to undertake inspection or testing of raw materials or purchased components.

In this concept the ITP contains the next chapters:

- Documentation - check receipt and availability of all required (approved) documentation (e.g. drawings, procedures, checklists, certificates, etc.)

- Personnel - check qualifications of welders, qualifications of inspectors, qualifications of NDT operators [6-9]

- Tools - check if certificates of required tools are available and correct (e.g. tools for weighting, lifting, measuring, welding, cutting, etc.)

- Material - check if certificates of required materials are available and correct, check if received materials are delivered as ordered (e.g. type, size, weight, etc.), check materials heat numbers, check storage conditions for materials and consumables 
- Cutting (plasma or oxy-gas) - approval of cutting plan, check performance and calibration of the cutting equipment and measuring tools, check environmental conditions, check dimensions after cutting, check material ID's of cut loose parts (tag numbering), check cut ends

- Welding - approval of welding procedures specifications, approval of welding performance qualification, check performance and calibration of welding machines and equipment for monitoring, check consumables; check environmental conditions, check welds, check repaired welds.

- Non-destructive Test - approval of NDT procedures, check qualification of NDT technician, check performance and calibration of NDT equipment, NDT test full / partial penetration welds using ultrasonic testing, NDT test filler welds using magnetic powder testing [6-8]

- Blasting and coating - check if certificates of required blasting abrasive particles and painting consumables are available and correct, check if received abrasive particles and paint are delivered as ordered [5]

- Final inspection - performing a final visual inspection, dimensional control (size, weight)

- Final release and documentation - approval of final documentation, final release

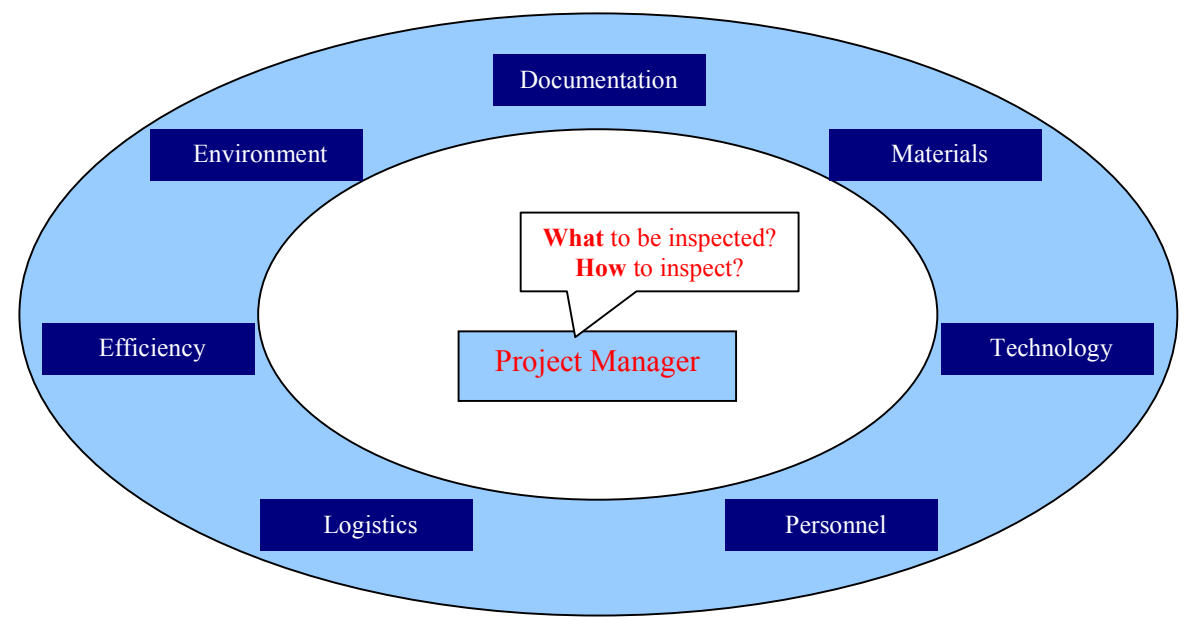

Fig.2 The questions of the Project Manager answered by the ITP

That means that the ITP should address exactly the outputs which are under the control of the Processes Coordinators, in the classic QM. Within the new concept, the Project Manager approaches the Coordination relations from the end to the beginning. He puts the question: what should be inspected and how? And his answer is the ITP document.

The essence of the questions is the same, but the shape depends on the process involved in fabrication.

\section{Cutting process}

To prepare the pieces to be assembled within the naval structure means the cutting from the raw materials the appropriate shapes and dimensions, according to the nesting. The ITP for this process should follow the next steps. 


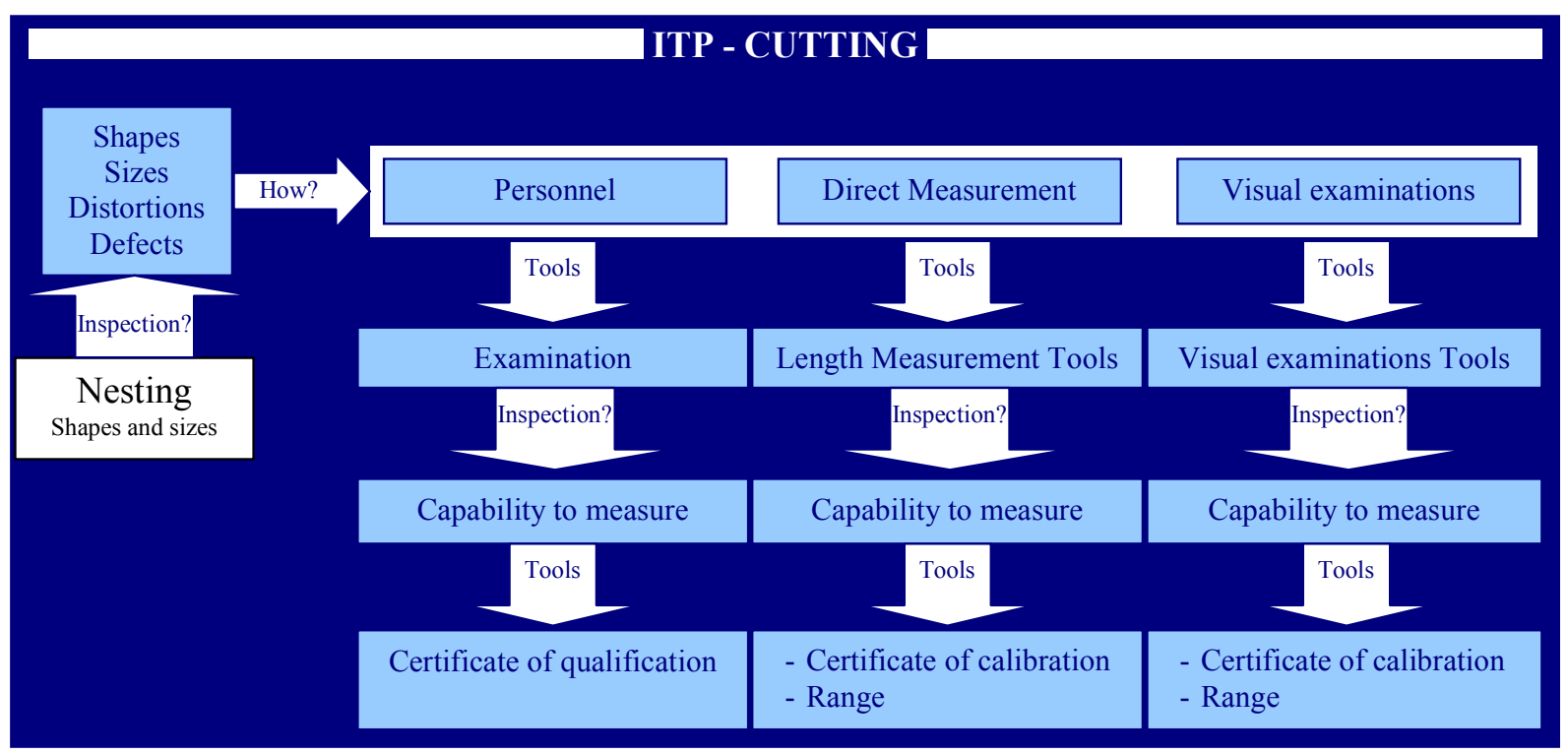

Fig.3 The ITP for cutting for the new QM concept

The cut pieces could suffer deviations from shapes and sizes, distortions or different types of defects specific to the cutting by using the applied technology. How can inspect all of these? First of all (Figure 3), by analysing the capability of the personnel to perform the jobs and that means the evaluation of the qualification and certification of the personnel. Secondly, the inspection should address the shapes and the dimensions of the piece and of the potential distortions or defects. That means direct measurement or visual inspections by using specific tools and the inspection should address the certification of calibration and the range of the tools.

\section{Welding process}

The welding of the cut pieces is the process which mostly affects the quality of the construction and the impact with the environment. The quality of the welds can not be directly evaluated and because of that ISO3834 gives to the welding the definition of "special process". Which problems are often met in welding and inspection on them is required? The influence of the welding process on the quality of the welds, respectively on the quality of the construction, is multiple.

It is necessary to apply inspections on the weld (imperfections, mechanical characteristics, geometry, dimensions, heat affected zone - HAZ, etc.), on the materials and consumables, on the personnel, on the technology, on the impact to the environment, etc. The ITP for the welding process should follow the next steps.

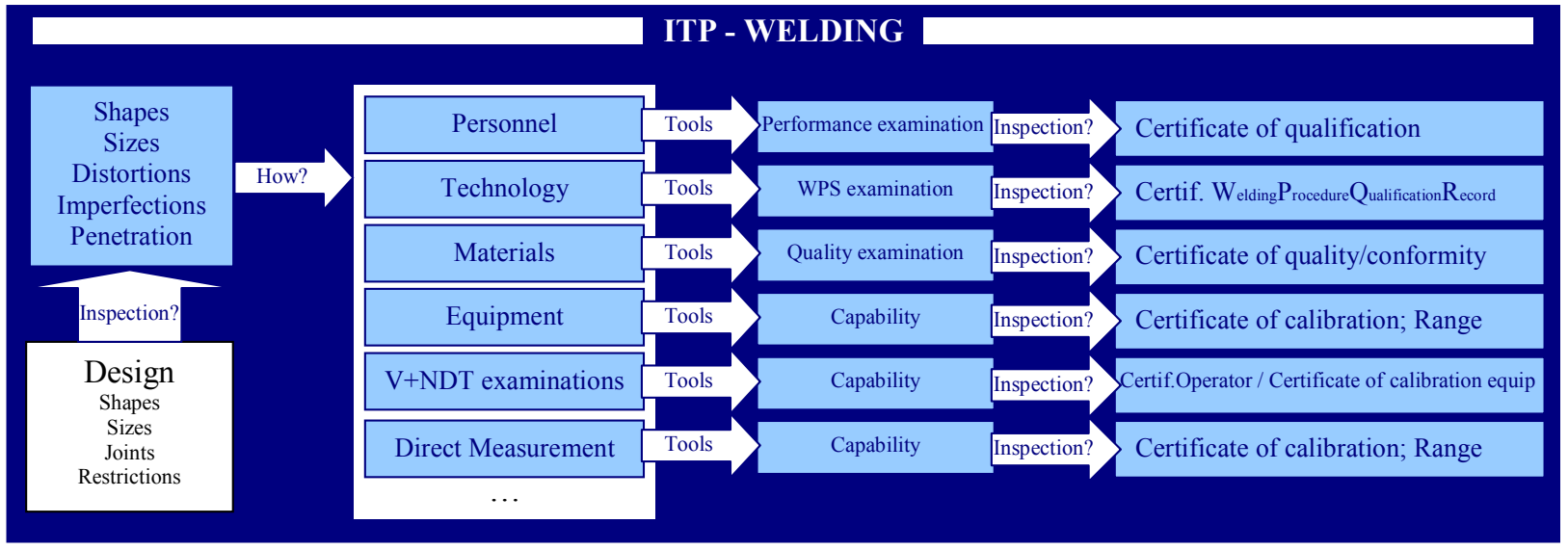

Fig.4 The ITP for welding for the new QM concept 
The restrictions regarding the welds are related to the shapes, the sizes and the penetration on one hand and material imperfections and distortions on the other hand. All of these should be inspected and the direct elements subjected to inspection are (Figure 4):

- the qualification of the personnel - where examination of the welders performances is proved by the certificates of qualification

- the approved technology - where the procedure should be qualified and this is proved by the existence of the qualified WPSs, so by the Welding Procedure Qualification Records

- the quality of the base materials and consumables (welding wires, electrodes, shielding gases, fluxes) - proved by the certificates of quality/conformity issued by the producer or after own testing

- the equipment - which should be able to implement the technology and this is proved by the certificate of calibration and by its own range of work

- Visual and NDT examination applied on site just next to the welding - the inspection should reveal the capability of the operator to perform the examination and this is proved by the qualification certificates of the NDT operators and by the certification of calibration of NDT equipment; usually, only visual examination is applied directly after the welding process but for special construction, like LNG tanks, NDT examination is required as well; for usual naval constructions NDT examination is applied after specific sequences of fabrication or only in the end of the fabrication

- Direct measurement - reveals the conformity of the shape, dimensions and distortions.

\section{NDT examination process}

The NDT examination of the welds is mandatory step after the fabrication and sometimes after specific sequences of fabrication. The examination is full regulated by standards and the questions of the Project Manager regard the personnel involved in the examination process, the consumables (penetrants and developers, magnetic powders, grease for US testing), the used equipment, which should be calibrated, and the direct measurement, where necessary.

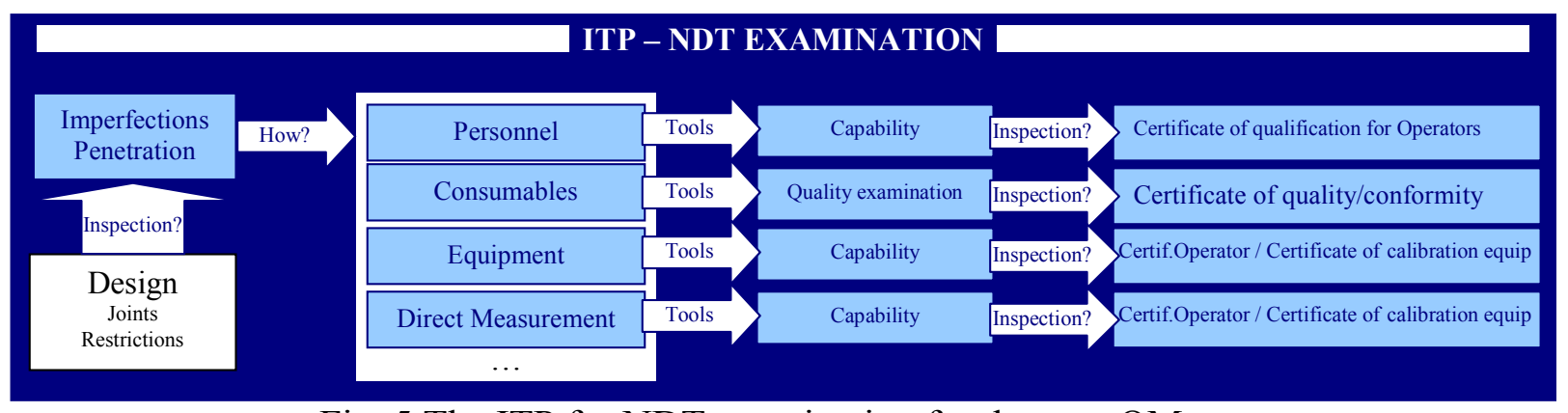

Fig. 5 The ITP for NDT examination for the new QM concept

The NDT examination has two levels of conditions: standard conditions and specific restrictions. First are introduced by the international regulations and the second is an input of the beneficiary or an input of the surveyor. If the regulations are not under discussions, the second set of inputs is related to the type of the examination method to be applied, to the volume of application and the position where to be applied. More, a version of the type of the examination method could be a restriction, as well. For example, because of the higher resolution of the film X-Ray method can be asked instead Gamma-Ray method, or because of the multiple answers a Phased-Array UT could be preferred to standard UT. All of these should be inspected and the direct elements subjected to inspection are (Figure 5):

- the qualification of the personnel - where the capability of the NDT operators is proved by the certificates of qualification 
- a map of examination - the inspector should confirm the positions and the volume of the examination and that is possible by approving a specific map proposed by the shipyard or by the surveyor

- the quality of the consumables (penetrants and developers, magnetic powders, grease for US testing) - proved by the certificates of quality/conformity issued by the producer

- the equipment - which should be able to reveal the imperfections inside the weld material and this is proved by the certificate of calibration and by its own range of work

- Direct measurement - reveals the sizes of an imperfection or the length which contains specific volume of imperfections.

\section{Straightening process}

The welding process applied on steels or on aluminium alloys, both of them as the most used materials in a shipyard, creates distortions (Figure 6). By applying appropriate technology (optimized heat input, optimized order of welding passes, choosing the most recommended welding process for a specific application, etc.) it is possible to maintain to a low level the distortions due to not uniform heating of the base material sheet. The application of the new concept starts with the input information which is the necessity to evaluate the distortions comparing to the approved tolerances. To the question "How?" will respond the personnel involved in the straightening process and they need to be qualified for that task, will respond the method which is applied and which should be performed according to an approved procedure (mechanical or thermal straightening, thermal with or without accelerated cooling, order of heating, etc.), will respond the equipment which is used to reduce the distortions and the direct measurement applied to evaluate the distortions and their evolution.

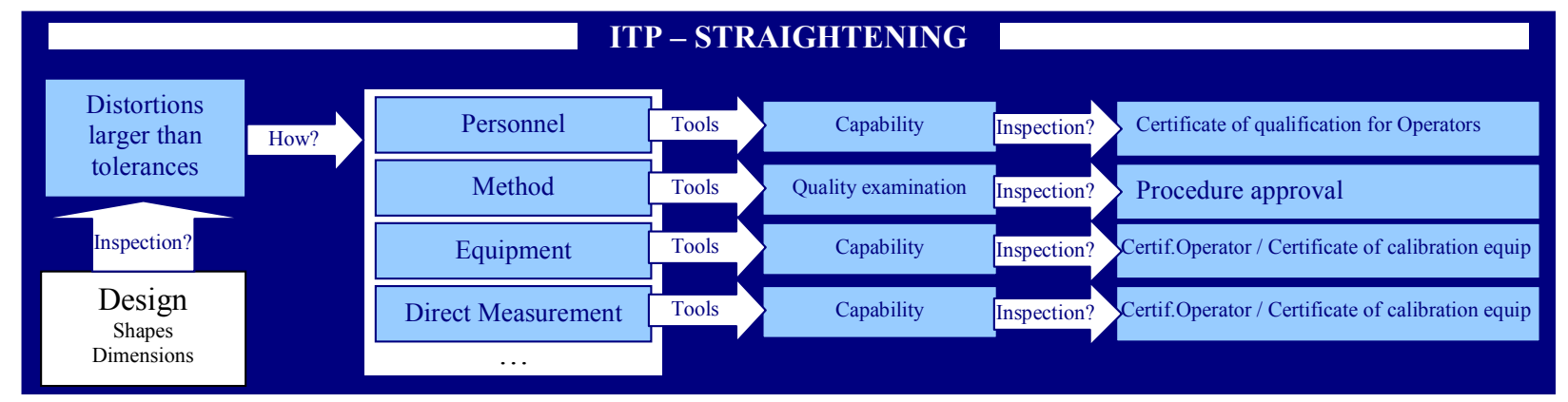

Fig.6 The ITP for straightening for the new QM concept

\section{Blasting and painting}

Blasting and painting increase the life of the naval structure. Because of that, under discussion are the personnel, the consumables, the technology and the direct measurement of the coating layer(s) (Figure 7). When the Project Manager or the Coordinator of the Painting ask about the technology they should consider as very important to create specific procedures for every step to be followed because every type of paint has its own specificity regarding the coating process.

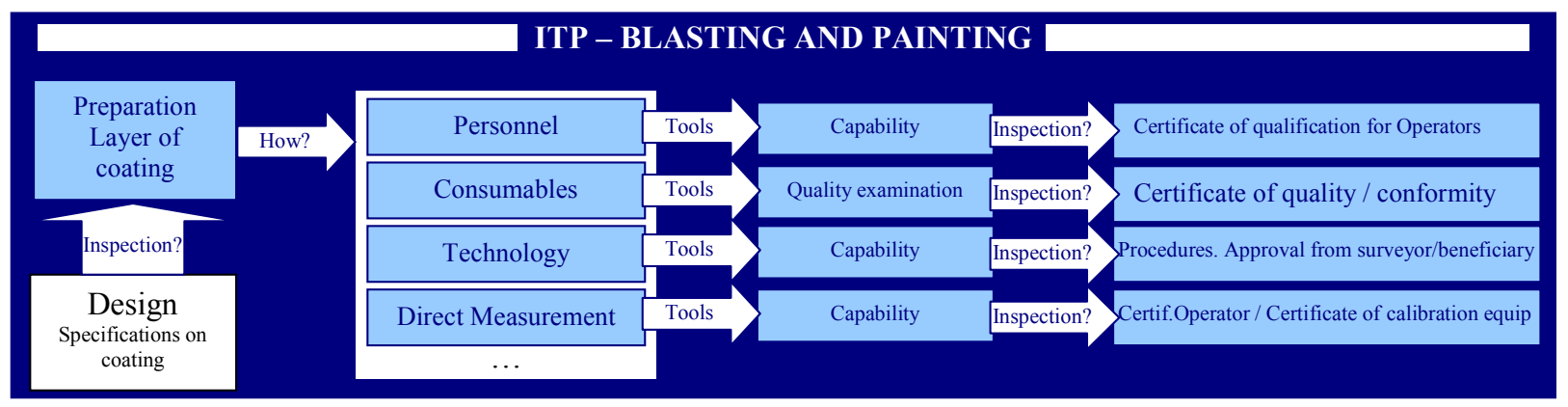

Fig.7 The ITP for blasting and painting for the new QM concept 


\section{Using the outputs of the new system}

Knowing the outputs of the ITPs (what to be inspected and how to be inspected), it is necessary to go back to the parameters of the discussed processes which influence the elements required to be inspected. Optimization of those parameters is the task to be taken by the Project Manager, in order to have the best results when inspection will be applied.

1. CUTTING

- What type of cutting process to be applied? Analyzing of the opportunities is required in this step: plasma cutting, oxy-gas cutting, laser cutting, water-jet cutting, mechanical or else. The optimization should be done by using specific criteria: distortions produced by process, width of the cutting, prints on the cut area, oxidation of the cut area, etc.

- Technological parameters? Optimization of the cutting parameters taking account of the nesting solution. High productivity could involve distortions larger than tolerances, so optimization is required.

- Choosing the most recommended consumables and verify their quality

- Training, qualification and certification the personnel dedicated to cutting and auxiliary operations

- Marking of the cut pieces.

- Recordings

\section{WELDING}

- What type of welding process to be applied? Arc welding, laser welding, laser-arc hybrid welding? What version is the most recommended? GMAW, FCAW, SAW, TWIN-GMAW for arc welding, or Laser-GMAW hybrid welding for hybrid systems? Analyzing is required from technical and economical point of view, taking account of the elements that will be inspected during and/or after fabrication.

- Technological parameters? Optimization of the welding parameters taking account of the distortions which could appear. Voltage, Current and welding speed to control the heat input together with the weaving, angle of the torch or heat treatments if necessary should be optimized taking account of shape and sizes of the weld, of distortions and imperfections, all of these being subjected to inspection (Visual examination, NDT examination, direct measurement or else).

- Elaboration and qualification of the WPSs

- What is the best technique to realize the weld?

- Choosing the most recommended consumables (welding wires, electrodes, shielding gases, fluxes) and verify their quality by analyzing the certification of conformity or by performing own testing.

- Elaborate procedure for storage and handling of consumables (temperature, humidity, etc.)

- Training, qualification and certification the personnel dedicated to welding, according to the regulations

- Repairing process (re-welding after the removing of the damaged welds or the welds with defects) to be done using the same technology as the welding.

- Recordings

\section{NDT EXAMINATION}

- What examination method to be applied? Is it necessary combination of 2 or 3 or even 4 methods? Analyzing is required from technical and economical point of view (taking account that the Radiation Testing is expensive and it brings specific issues regarding the safety of the personnel.

- What is the volume of application for every method of examination considered?

- What is the position to apply a method which is in lower than $100 \%$ volume? Map of the examination is required to be designed. Approval of the map is required. 
- Technological parameters? Optimization of the control parameters taking account of the restrictions regarding the dimensions of the imperfections.

- What is the best way to combine the methods in order to be sure that all the imperfections will be revealed?

- Choosing the most recommended consumables for NDT examination methods and verify their quality by analyzing the certification of conformity or by performing own testing.

- Training, qualification and certification the NDT operators to the required level (min level 2), according to the regulations

- Recordings

\section{STRAIGHTENING}

- What type of deformation process to be applied? Thermal by flame or mechanical by cold deformation or mix of them? Is it permitted to use water to cool down? Analyzing is required from technical and economical point of view, taking account of the elements that will be inspected during and/or after fabrication.

- Technological parameters of the straightening?

- Elaboration of specific procedure which should be approved by the surveyor or by the beneficiary

- What is the best technique to apply heating or hammering?

- Recordings

\section{BLASTING AND PAINTING}

- Remove oil, grease or other contaminations by solvent cleaning accordance SSPC-SPI63.

- Protect no blasting parts against damage by abrasive blast cleaning (tape, plug, caps etc.)

- What is the best abrasive grit to prepare the surface? Certificate of conformity should be analyzed before use.

- What are the best primer and the most appropriate paint? Certificate of conformity should be analyzed before use. Blasted and cleaned surfaces must be free of blast residues (vacuum cleaning and/or stiff brushing), dust or grit and keep free from any contamination. Prepared surfaces must be coated before end of working period and within maximum of 4 hours after blasting

- Elaboration of specific procedure for blasting and painting which should be approved by the surveyor or by the beneficiary (ISO 8501-1)

- Elaborate procedure for storage and handling of consumables (temperature, humidity, etc.)

- Elaboration of specific procedure for measurement of the paint layer thickness. Define measurement points. No deviations dry film thickness greater than $25 \%$ above or $15 \%$ below the nominal value specified. At least one per square metre and two measurements at each defined measurement location

- Elaboration of specific procedure for repairing

- Elaboration of specific procedure for tests on the paint adhesion (Minimum required adhesion is $5.0 \mathrm{MPa}$ ).

- Recordings.

\section{Conclusions}

Usually, in a shipyard the QM starts with the organizing of the conditions to apply the processes involved in fabrication. In the end, the inspection of the construction will create feed-back which means repairing and corrections. New concept of QM is introduced. The concept consists in starting with the inspection conditions and to optimize the intermediate parameters in order to have the best input in fabrication. 
ITP is the main tool to analyze the future inspection. It is used to understand which parameters should be optimized before starting the fabrication.

ITP concept consists in set of questions which should be asked to the system by the Project Manager of by the Coordinator of process. The main questions are: What to be inspected? How to inspect?

ITP is specific to all the involved processes: cutting of the pieces from metal sheet, according to the nesting; welding of the cut pieces according to the design of the naval structure.

Technological solutions are facile to elaborate after the implementation of the developed ITPs.

After the application of the new system in the Shipyard Kladovo fabrication the reparation of the welded structures due to the distortions after the welding processes and the reparation of the paint layer decreased in volume with more than $20 \%$ comparing to the old quality management system. The Project Manager was able to apply prevention and to better control the quality of the fabrication.

\section{References}

[1] R.L. Storch and Jon R. Gribskov: Accuracy Control for U.S. Shipyards, Journal of Ship Production, Vol. 1, No. 1, Feb. 1985, pp.64-67

[2] D. L. Goetsch, S. B. Davis: Total Quality Handbook, Prentice-Hall, New Jersey, 2001

[3] S.N. Chapman: The Fundamentals of Production Planning and Control, Prentice Hall, ISBN-13: 9780130176158, 2005

[4] Dale H. Besterfield, et al., "Total Quality Management," Second Edition, Prentice-Hall,New Jersey, 1999

[5] T. Magheţ, J. Maehrlein: Durabilitatea produselor utilizate pentru construcţii - Protecţia împotriva coroziunii - Cerinţe şi calificarea personalului, Sudura no. 2/2014

[6] D. Stan, I. Serban, A. Sîrbu, A. Tulcan: Study on the resonant frequency gliding in the ultrasonic systems loaded with variable axial compression force, ModTech International Conference - New face of TMCR Modern Technologies, Quality and Innovation - New face of TMCR, 24-26 May 2012, Sinaia, Romania, ISI Proceedings

[7] P. Tenchea: Evoluţii ale standardizării în domeniul examinării cu radiaţii penetrante a îmbinărilor sudate ale oţelurilor, Sudura no. 1/2014

[8] O. Oancă, N. Paşca, N.A. Sîrbu, E. Dimian: Ultrasonic welding simulation for metallic materials, ModTech International Conference-New face of TMCR „Modern Technologies, Quality and Innovation", 2011, p. 773-776

[9] D. Dehelean, P. Ţenchea: Formarea şi calificarea personalului sudor de execuţie - Analiza sistemului din România comparativ cu sistemul european/internaţional şi din alte ţări şi propuneri de îmbunătăţire, Sudura no. 2/2014 